\title{
AN AID TO GENERAL ANAESTHESIA FOR BRONCHOGRAMS
}

\section{W Bowering, C.D., M.D., F A C A.}

General anaesthesia for bronchograms at Regina General Hospital has been greatly simplified by a modification of a technique published by Dr. A. H. L. Baker in the British Jourrall of Anaesthesia (1).

The anaesthetic agents we have been using are thiopentone, succinylcholine by drip, and nitrous oxıde After induction the patient is intubated using a cuffed endotracheal tube or a snug tube in children. This endotracheal tube is fitted with a Cobbs Suction endotracheal connector. In addition to the regular solid plug for the suction mlet, Dr. E Asquith has designed and machined plugs fittng the suction inlet which are drilled with a hole that accommodates a farr sized polyethelene tube without binding or leak. As unfortunately the suction inlets of all Cobbs Connectors are not uniform in size, this plug must be tested for fit to the Cobbs Connector before use

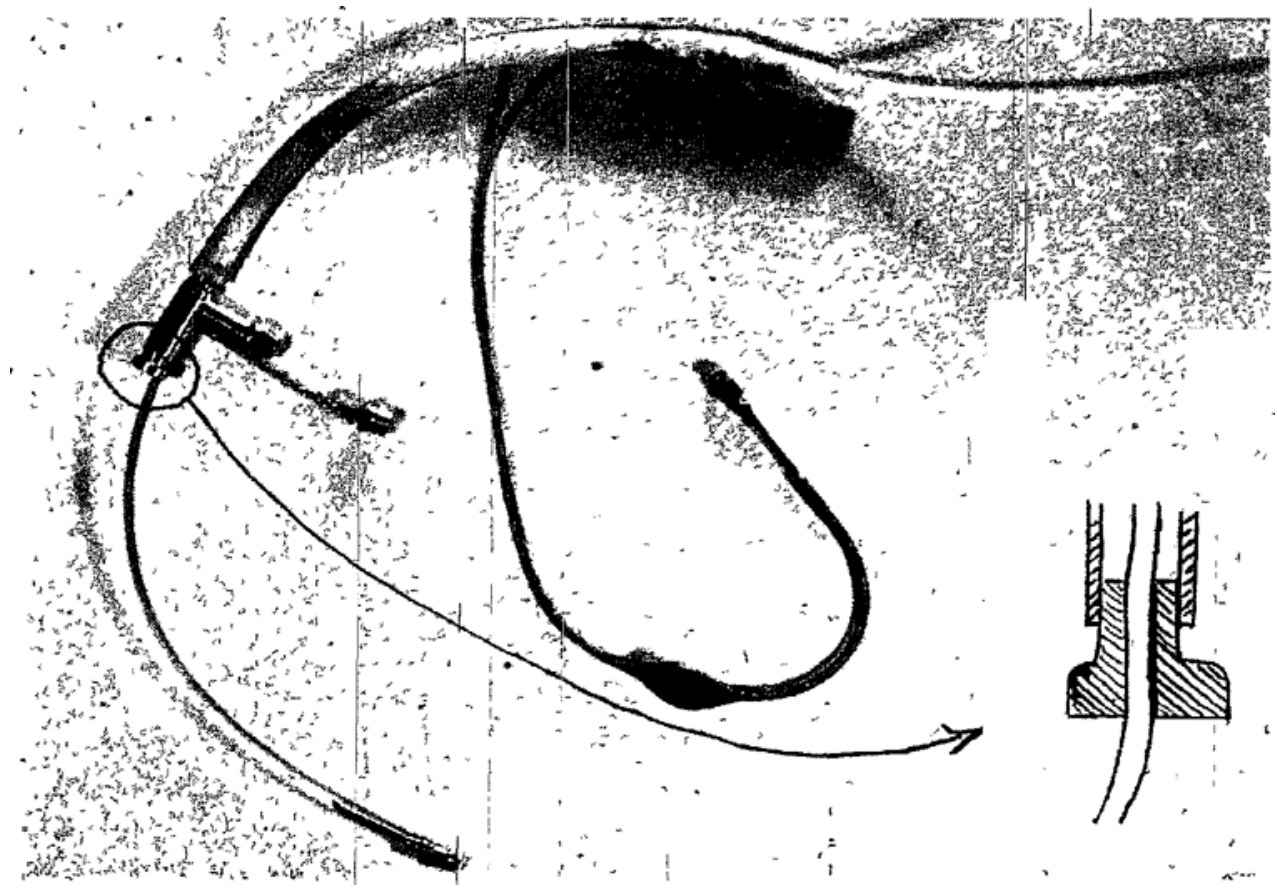

Figure 1

The polyethelene tube is several inches longer than the endotracheal tube and connector and is fitted on the external end with a round-based needle to fit the injecting syrnge or suction tubing. Prior to use of this plug and tube, the tube is filled with opaque medium. With the patient almost apnoeic, the modified plug and tube are substituted for the solid plug of the Cobbs Connector, and the polyethelene tube is manipulated under fluorscopy to the area in which it is desired to place the medium 


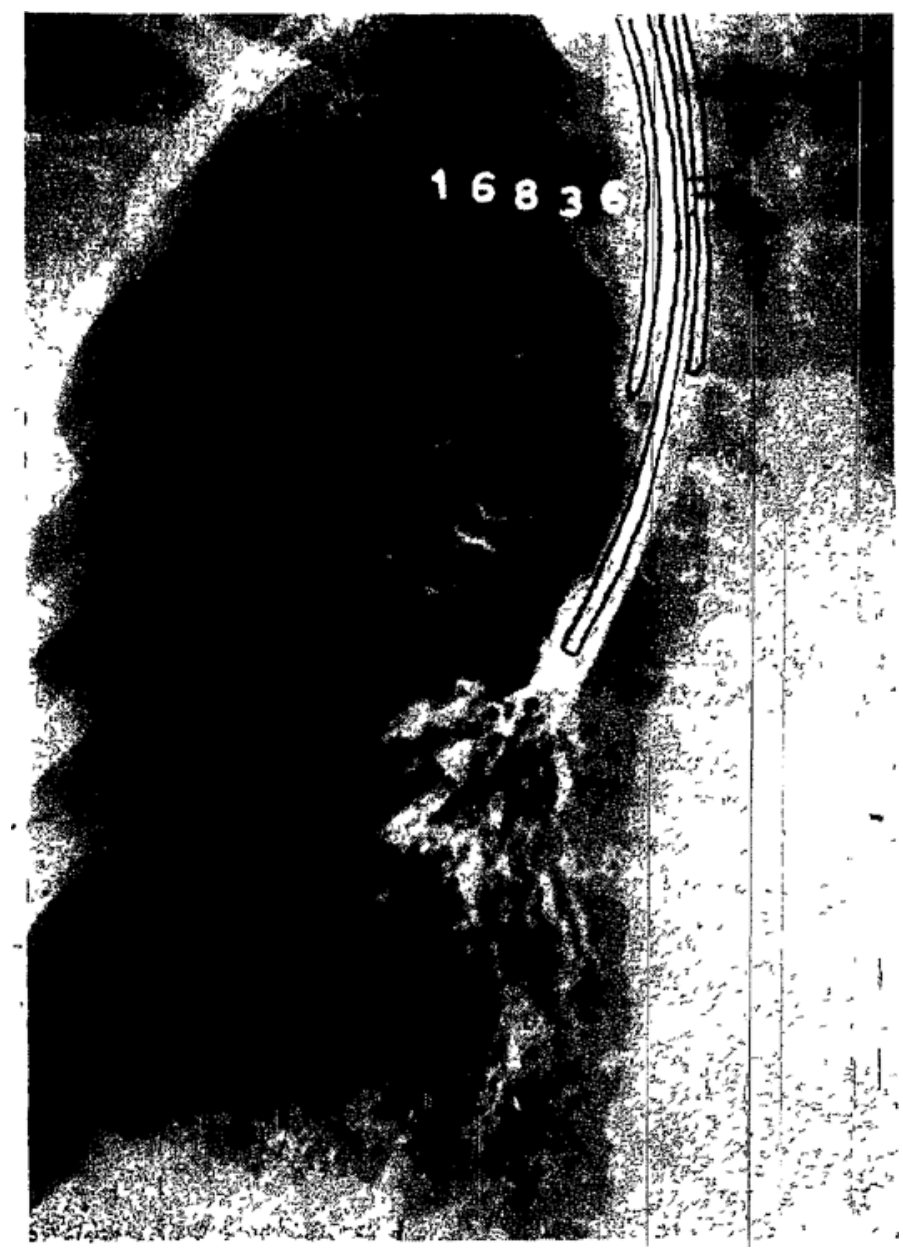

Figure 2

The medium is unstilled while slow deep controlled respirations are imposed on the patient. These controlled respirations spread the medium evenly and we have found that the amount of medium needed is munmized.

After the plates have been taken, as much of the medium as is possible is suctioned out, using the same polyethelene tube.

This technique has the following benefits: (1) absolute control of respiration; (2) ease of placement of the opaque medium, (3) ease of recovery of a proportion of the medium.

\section{REFERENCE}

1. Baker, A H L Endotracheal Lipiodol under General Anaesthesia in Children Brit. J Anaesth 17(3) (Jan, 1941) 